\title{
The Low Income Housing Tax Credit and Racial Segregation
}

\author{
Keren M. Horn \\ Doctoral Fellow \\ Furman Center for Real Estate and Urban Policy \\ NYU Wagner Graduate School \\ 212.998.6437 \\ kerenhorn@nyu.edu
}

Katherine M. O'Regan

Associate Professor

NYU Wagner Graduate School

(212) 998-7498

Katherine.ORegan@nyu.edu

May 2, 2011

Acknowledgements: We would like to thank the states of Massachusetts and Delaware for sharing with us data on the tenants of tax credit developments within their state. We would also like to thank the Furman Center for Real Estate and Urban Policy and the Robert F. Wagner Graduate School of Public Service for their support of this project. We specifically thank participants in the Furman Center brown bag series for their comments, and in particular, Ingrid Gould Ellen, Adam Gordon, and Vicki Been. 


\begin{abstract}
This paper addresses a critical but almost unexamined aspect of the Low Income Housing Tax Credit (LIHTC) program - whether its use (and in particular, the siting of developments in high poverty/high minority neighborhoods), is associated with increased racial segregation in the metropolitan area. Using data from HUD and the census, supplemented with data on the racial composition of LIHTC tenants in three states, we examine three potential channels through which the LIHTC could affect segregation: where LIHTC units are built relative to where other low income households live, who lives in these tax credit developments, and changes in neighborhood racial composition in neighborhoods that receive tax credit projects. The evidence on each of these channels suggests that LIHTC projects do not contribute to increased segregation, even those in high poverty neighborhoods. On net, we find that increases in the use of tax credits are associated with declines in racial segregation at the metropolitan level.
\end{abstract}




\section{Introduction}

The Low Income Housing Tax Credit (LIHTC) program is currently the largest place-based subsidized housing program in the country. By the end of 2007 , over 1.8 million LIHTC units had been placed in service, in comparison to under 1.2 million units of public housing. ${ }^{1}$ However, unlike subsidized housing provided through the Department of Housing and Urban Development (HUD) the tax credit is administered by the Internal Revenue Service (IRS), and as such the LIHTC program has not been subject to the same level of oversight through fair housing codes as HUD programs, particularly with respect to where developments are sited. Moreover, developers who build in Qualified Census Tracts (QCTs), which are high-poverty neighborhoods that often have high minority concentrations, are awarded higher tax credit amounts and given priority by state and local housing agencies when credits are allocated. A growing number of advocates and observers worry that the lack of oversight, coupled with the priority given to developers building housing in high poverty census tracts, also leads to developing LIHTC units in areas of minority concentration, potentially heightening segregation. ${ }^{2}$ In fact, this issue has been raised in several lawsuits against state allocating agencies, in which litigants have sought to limit the siting of LIHTC developments in neighborhoods of high minority (and poverty) concentration. Yet it is precisely such locations and uses of the tax credit that community development advocates claim can be crucial in community revitalization efforts.

\footnotetext{
${ }^{1}$ Picture of Subsidized Housing 2008, Department of Housing and Urban Development.

2 Poverty and Race Research Action Council (PRRAC). 2004. Civil Rights Mandates in the Low Income Housing Tax Credit Program. http://www.prrac.org/pdf/crmandates.pdf
} 
Using data from HUD and the census, supplemented with data collected on the racial composition of LIHTC tenants in three states, this paper aims to addresses this critical but almost unexamined aspect of the Low Income Housing Tax Credit programwhether its use may be associated with increased levels of minority segregation. To date, the primary empirical evidence used to speak to this question is simply the racial composition of tracts where developments are sited. This stops short of assessing whether such siting contributes to increased segregation, which also depends on where tenants would otherwise live, who the tenants are, and whether neighborhood composition subsequently changes.

We address the first by developing a reasonable counterfactual for tenant locations: the tracts where poor renters and near poor households live, in the same metropolitan area. We find that LIHTC units are only slightly more likely to be located in high minority tracts than are units occupied by near poor and poor renters.

In terms of tenant composition, for the three states examined, we find that LIHTC tenants are disproportionately minority, and this is particularly true for developments in QCTs, those built by nonprofits and in central city tracts (two additional uses that tend to site in tracts of greater minority concentration). However, we also find that in some states a sizable portion of developments located in QCTs are not tracts with high minority concentration, and even those that are may contribute to lower levels of minority concentration in the surrounding neighborhood when tenant composition is taken into account. Examining changes in the racial composition of tracts in which LIHTC development occurs, we find that neighborhoods of high minority concentration experience declines in minority representation over time, rather than an increase. 
Finally, moving to the metropolitan level to consider the net-effect of these factors, we find that increases in the use of tax credits between 1980 to 2000 in metropolitan areas, are actually associated with declines in segregation. Furthermore, increased numbers of units in QCTs, by nonprofits, and in central cities are generally associated with declines in minority segregation.

We proceed by first describing the nuts and bolts of the LIHTC program, highlighting aspects that trigger concerns about its potential effects on segregation. We then lay out the specific ways in which LIHTC developments may influence patterns of racial segregation in metropolitan areas, and what is currently known about each of these dimensions. The subsequent section describes our data and empirical methods, which is then followed by our results and the conclusion.

\section{LIHTC Program}

The Low Income Housing Tax Credit Program was established in 1987 and has since become the primary source of federal support for creating place-based, affordable rental housing in the United States. It was created as part of the Tax Reform Act of 1986, which also removed a number of more general real estate and housing tax benefits. At its start, each state received $\$ 1.25$ per capita allocation, which has since been increased and is now adjusted for inflation. ${ }^{3}$ Developers competitively apply to their respective state for these credits and then use the credits to leverage private capital into acquisition, new construction or rehabilitation of affordable rental units.

All projects must meet a couple of general minimum requirements, including minimum affordability criteria. Either 20 percent of the units must be rent restricted and

\footnotetext{
${ }^{3}$ In 2007 each state received $\$ 1.95$ per capita in allocations.
} 
occupied by households whose income is below 50 percent of area median gross income or 40 percent of the units must be rent restricted and occupied by households whose income is 60 percent or less of area median gross income. ${ }^{4}$ Projects are required to retain eligibility for 30 years (increased from 15 years at the program's start).

Unlike other federal tax credits, the LIHTC is administered at the state level. Structured to permit state tailoring to local needs, each state is required to designate an agency to allocate tax credits, usually the state Housing Finance Agency (HFA). These allocating agencies are tasked with determining state priorities for the LIHTC program, and awarding credits. ${ }^{5}$ Since 2000 , all states are required to prioritize projects located in QCTs that "contribute to a concerted community revitalization plan" (Orfield, 2005). ${ }^{6}$

Various fair housing advocates have raised concerns that the LIHTC program may contribute to racial segregation. As stated by Philip Tegeler (Poverty and Race Research Action Council) on behalf of a coalition of civil rights and fair housing advocates: "There is a very long and well documented history of the use of Federal housing resources to create and perpetuate racial segregation in assisted housing. That same history is now repeated in the LIHTC program."7 The letter connects this outcome

\footnotetext{
${ }^{4}$ Though these developments were intended to be mixed income developments, in fact most are predominantly low income. Eighty-five percent of projects built by 2007 consist of over 90 percent low income units.

${ }^{5}$ States must submit yearly Qualified Allocation Plans (QAPs) that relate the priorities for use of LIHTC credits to local housing conditions and needs. The majority of criteria are shared across allocating agencies which reflect federal requirements, but states also impose their own priorities.

${ }^{6}$ Many states also provide 'points' in their ranking criteria for developments located in QCTs.

${ }^{7}$ In a letter to the I.R.S. Assistant Secretary for Financial Institutions, Domestic Finance, dated October 26, 2010. http://www.prrac.org/pdf/civil_rights_letter_to_Michael_Barr_10-26-10.pdf
} 
to the prominent use of LIHTC credits in neighborhoods of high poverty (and minority concentration). ${ }^{8}$

Similar concerns that state siting priorities might contribute to heightened racial segregation has been brought to court in several states. In 2002, the Connecticut Civil Liberties Union brought a case against the Connecticut HFA to the Connecticut Supreme Court, claiming that developments in Hartford were leading to increased racial segregation. ${ }^{9}$ In 2004, New Jersey’s Fair Share Housing Center brought a case against the New Jersey Housing Mortgage Finance Agency, requesting the inclusion of a requirement in the state qualified action plan (QAP) that the racial composition of neighborhoods be considered when determining which projects would receive credits (Shah, 2005). ${ }^{10}$ Currently another case is pending in Dallas, Texas, again charging that tax credit developments are being sited in neighborhoods of high minority concentration, and through these patterns perpetuating racial and ethnic segregation. There are a few features of the structure of the LIHTC program that are most relevant for concerns about its effect on racial segregation.

\section{Lack of direct HUD oversight}

\footnotetext{
${ }^{8}$ The issues raised by fair housing advocates are broader than this, including antidiscrimination enforcement in the implementation of the LIHTC and affirmatively furthering the goals of fair housing. We don't address these additional concerns in our work.

${ }^{9}$ In Re Declaratory Ruling on Connecticut Low Income Housing Tax Credit Program. The Connecticut Civil Liberties Union challenged the lack of civil rights guidelines in the siting of projects under the LIHTC in Connecticut and sought restrictions on future placement of low-income rental units in racially concentrated neighborhoods.

${ }^{10}$ While the court ruled that the New Jersey Housing Mortgage Finance Agency was obligated under the Fair Housing Act to prevent discrimination and promote integration, the court also found that the state agency did not have to take race into account in the QAP to promote integration, and that in fact the state was doing all that it could to promote integration given its other statutory duties and that New Jersey's 2003 QAP did not directly encourage racial segregation. In re 2003 QAP, 848 A.2d at 15.
} 
As opposed to most affordable housing programs, the LIHTC is a tax credit program and thus overseen by the Internal Revenue Service (IRS) rather than the Department of Housing and Urban Development (HUD). As such, the LIHTC program has not been subject to the same level of oversight in terms of fair housing codes as HUD programs, including HUD guidelines that discourage local housing authorities from locating new assisted housing in neighborhoods with high concentrations of poor and minority households. This fuels concern that tax-credit projects could increase levels of racial segregation, particularly those located in QCTs. ${ }^{11}$ This concern can also apply to developments in central cities, where low income housing has historically been built in neighborhoods of high minority concentration (Freeman, 2004).

\section{Qualified Census Tracts (QCTs)}

The amount of tax credits awarded to an individual project is based on the qualified basis, or estimated project costs, which depend on the nature of the housing (acquired, constructed, or rehabilitated), the presence of federally subsidized loans, and total eligible development costs. ${ }^{12}$ Projects that are built in qualified census tracts (QCTs), defined as neighborhoods where at least 50 percent of the households have incomes below 60 percent of their metropolitan area's median family income, receive a 30 percent bonus in their qualified basis. ${ }^{13}$ Baum-Snow and Marion (2009) find that QCT designation does increase the probability that a unit will be built in a QCT, and

\footnotetext{
${ }^{11}$ For a good review of the legal issues and advocates position, see Orfield, 2005.

${ }^{12}$ For a good overview of program details, see Schwartz et al, 2006.

${ }^{13}$ In 2000, the definition of QCT was modified so that localities could use a 25 percent poverty threshold instead, which on average is equivalent. Our empirical work ends in 2000, so we employ the original definition of QCT.
} 
examination of QCTs in 1990 shows that they do, on average, have a much greater minority concentration than non QCTs. ${ }^{14}$

Non profit vs. for profit

Federal legislation also requires that states set aside ten percent of their allocations for non-profit developers; many states set aside higher levels. While some states barely meet the federal target, on average the share of allocations going to non profits nationally is approximately 22 percent. ${ }^{15}$ This feature of the program has primarily not been at the heart of current concerns about segregation, but given its possible relevance for siting of projects, the composition of tenants, and possible spillover effects on neighborhoods, we raise it here. Specifically, if projects created by non profit developers are more likely to be located in high poverty neighborhoods, and serve poorer populations who are disproportionately minority, at least theoretically this use raises similar concerns about potential contributions to segregation. On the other hand, if non profit developers are more likely to undertake developments as part of a broader neighborhood development strategy, perhaps these developments contribute to decreased segregation over time.

\section{LIHTC and Segregation: Theory and Literature}

Could the tax credit program influence patterns of metropolitan segregation? In terms of scale, it appears possible. Overall, metropolitan LIHTC units placed in service by 2007 make up approximately $3.4 \%$ of the metropolitan rental housing stock. If we

\footnotetext{
${ }^{14}$ HUD 1990 QCT list and NCDB.

${ }^{15}$ LIHTC Database, HUD. This number is based on all three decades of development and calculated as a percent of units for which non-profit status is not missing. ( 80 percent of observations)
} 
look just at the rental units occupied by renters who fall within LIHTC income limits (below $60 \%$ of area median income ${ }^{16}$ ) then LIHTC units comprise $10.2 \%$ of this housing stock in metropolitan areas, on average. Given the scale of the LIHTC program its use could affect the spatial distribution of the low income population, and the likely disproportionately minority households that use it.

There are a number of ways through which LIHTC developments may influence metropolitan patterns of racial segregation. As a direct consequence of the siting of projects (and their tenants) in particular neighborhoods, the LIHTC program alters spatial patterns of households. Adding new units - and new residents - to a neighborhood may alter the neighborhood's racial composition, and ultimately segregation. ${ }^{17}$ Of course, how this siting decision affects a neighborhood's composition depends on the racial composition of the tenants. In addition, these new residents could have lived in a different neighborhood in the absence of the LIHTC program. Therefore the development may also alter the composition of other neighborhoods in the area, by removing households who would otherwise have lived there. The direct (and perhaps immediate) effect of LIHTC developments on segregation will depend on all three of these dimensions - where units are sited, the composition of the tenants, and where those tenants would have lived absent the LIHTC. In addition, LIHTC developments remain low income for thirty years. The composition of their surrounding neighborhoods may change systematically over time in ways that alter the program's effect on segregation over the life of the housing. The net effect of LIHTC developments on segregation depends on the combination of these factors, across all neighborhoods.

\footnotetext{
${ }^{16}$ This estimate is based on Census Public Use Micro data, for all metropolitan areas in the LIHTC data. ${ }^{17}$ While some tenants could come from the surrounding neighborhood, developers are prohibited from prioritizing residents of the surrounding neighborhoods in their tenant selection process.
} 


\section{Siting}

The most obvious and direct way in which LIHTC investments might further racial segregation is through siting of developments. Empirical work on where these units are located, and in particular, concern over the priority given to QCTs, has focused on the racial composition of tracts receiving the LIHTC project. The presumption is that locating projects in tracts with relatively high concentrations of minorities in and of itself increases segregation.

Freeman (2004) examines the location of tax credit projects and finds that their neighborhoods do have a high concentration of minority residents, specifically that one in four residents of LIHTC neighborhoods is black, whereas only one in seven residents across all metropolitan neighborhoods is black. Focusing on a small sample of tax credit developments, Buron, Nolden, Heintz and Stewart (2000) find that projects built by non profit developers are overwhelmingly sited in neighborhoods of high minority concentration whereas projects built by for profit developers are more evenly distributed across neighborhood categories of racial concentration. ${ }^{18}$ Such siting evidence has been taken to suggest that tax credit developments, and particular uses of tax credits, do heighten metropolitan segregation.

The other half of the story, however, is often overlooked - namely, where households would have ended up had it not been for the LIHTC program. In order for such siting of LIHTC developments to increase patterns of racial segregation it must be moving minority households into areas of higher minority concentration than they would

\footnotetext{
${ }^{18}$ They report that $61 \%$ of projects built by non profit developers are located in neighborhoods categorized as high minority.
} 
have lived absent the program. Thus the key question is whether tax credit projects are located in neighborhoods with a higher share of minorities than the neighborhoods in which those LIHTC tenants would live absent the opportunity to live in a subsidized, tax credit unit. ${ }^{19}$ Recent evidence from the Moving to Opportunity program reminds us that even with portable rent subsidies, subsidized housing recipients tend to live in fairly highpoverty (and therefore high minority) communities (Goering, 2005).

Two existing studies have compared the locations of LIHTC developments to those of other assisted housing programs. Freeman (2004) finds that overall LIHTC developments are built in neighborhoods with a higher share of white residents than other federally subsidized housing developments. McClure (2006) focuses solely on poverty rates of surrounding neighborhoods. He finds that suburban LIHTC developments are more likely to be located in low poverty neighborhoods than housing choice voucher holders and that there is no difference in residential outcomes in the central city. These analyses, however, focus solely on other assisted households and are national in scope. As a more appropriate counterfactual for where actual residents of LIHTC developments might otherwise live, we improve on such analysis by comparing the distribution of LIHTC units to the distribution of all low income households and poor renters within the same metropolitan area.

Finally, all of this analysis has ignored another key issue in the possible effect of siting on segregation - the racial composition of tenants.

\section{Tenants}

\footnotetext{
${ }^{19}$ An alternative counter factual is to consider where these households would live if the LIHTC siting patterns differed - i.e., QCTs were not prioritized. We do not address this directly, but believe our MSA regression results shed some light on such a comparison.
} 
Any siting effect of the LIHTC developments also depends on the racial composition of the tenants themselves. Up until recently there has been no federal mandate requiring the collection of tenant demographic data, thus we know very little about the racial characteristics of the LIHTC tenants themselves. ${ }^{20}$ There are, however, two studies that collected and examined data about characteristics of LIHTC tenants for a limited set of LIHTC developments.

In a random selection of 423 tax-credit projects placed in service between 1992 and 1994 the United States General Accounting Office (GAO, 1997) found that the majority of tax credit tenants are white, (53 percent) and 33 percent of tenants are black. In contrast, Buron, et al (2000) sampled 39 LIHTC properties placed in service between 1992-1994 in five MSAs and found that over 80 percent of the residents in these developments are minorities, primarily black (56 percent) and Hispanic (20 percent). Comparing the racial mix of the development to that of the neighborhood, they found that over half of the LIHTC properties have a higher share of minority households than the neighborhood $^{21}$ suggesting that LIHTC developments may be contributing to the concentration of minority households in the surrounding neighborhood. They also found that all the properties which have a lower share of minorities than the neighborhood had a for-profit sponsor. ${ }^{22}$

These limited studies suggest there may be wide variation in the racial composition of LIHTC projects, and perhaps that there is important variation by the

\footnotetext{
${ }^{20}$ As of 2011, states are now required to collect and provide to HUD data on tenants but providing data on race is currently voluntary.

${ }^{21}$ Specifically they find that 44 percent have about the same share of minorities as the neighborhood, and only 5 percent have a substantially lower share of minority households than the neighborhood.

${ }^{22}$ They also found that for-profits were much more likely than non-profit developers to build in neighborhoods that have a similar share of minorities as the neighborhood, 65 percent as compared to 26 percent.
} 
sector of the developer. We add to the existing knowledge on LIHTC tenant composition by collecting data on the racial composition of LIHTC tenants in three states, which includes over 1,500 developments and over 170,000 households.

\section{Changes in neighborhood racial composition}

The LIHTC program could also have indirect effects on neighborhood racial composition, and thus metropolitan racial segregation. As community development advocates and others suggest, an LIHTC development may improve a distressed minority neighborhood, making it more attractive to white households through removing blight, building attractive new housing, repopulating a community, and/or inviting other investment and improvements (Baum-Snow and Marion, 2009; Eriksen and Rosenthal, 2007; Schwartz, Ellen, Voicu and Schill, 2006). The limited empirical work on this provides mixed evidence, from small negative effects on the growth of assessed values in Iowa (Funderburg and MacDonald,2010), to some evidence of positive effects on surrounding property values in two MSAs in Wisconsin (Green, Malpezzi and Seah, 2002) and some evidence of significant increases in property values for nearby properties in New York City (Ellen, O’Regan and Voicu, 2008).

Freeman and Rohe (2000) examine the relationship between assisted housing development and neighborhood racial change, finding some limited evidence that LIHTC developments placed in service during the 1980s may contribute to a very small decline in the share of the neighborhood population that is white, at least in neighborhoods most likely to receive such developments (which tend to be high minority). This paper, however, focuses on a very small number of LIHTC developments, as the program was 
not created until 1987. More recently, Deng (2007) also explores the relationship between LIHTC developments and neighborhood level racial change, conducting a detailed analysis of developments in Miami-Dade county, Florida. When comparing LIHTC neighborhoods to a set of controls identified through a cluster analysis, she finds that LIHTC neighborhoods were more likely to experience a set of positive changes, including decreased minority concentration and poverty rates, than these control neighborhoods. ${ }^{23}$ Overall, while limited in geographic scope, these findings suggest there may be some merit to the potential of LIHTC projects to revitalize a neighborhood, although this likely differs by context and development characteristics. At a minimum, this work suggests that focusing on the racial composition of a neighborhood at the time of siting may provide an inaccurate picture of the effect of such siting on racial segregation.

Our paper is the first to consider such changes in neighborhood racial composition surrounding LIHTC developments at a national scale with recent data. It is worth pointing out that the two studies reviewed above are explicitly attempting to determine a causal relationship between the presence of LIHTC developments and subsequent changes in a neighborhood's racial composition. Alternatively, there may be no causal relationship, but a systematic relationship nonetheless, through selection and other factors. Such a non causal relationship between LIHTC developments and racial composition at the neighborhood level can nevertheless affect metropolitan segregation in a causal way. To illustrate, if developers select locations that are expected to improve economically, hence are already on a path of declining minority population, there may be

\footnotetext{
${ }^{23}$ Additionally Deng (2007) finds that LIHTC projects built in the highest poverty neighborhoods are the most highly correlated with positive changes whereas similar investments in middle class neighborhoods are the most highly correlated with negative changes.
} 
no causal relationship between the siting of LIHTC and that neighborhood's subsequent decline in minority concentration. Such selection in siting, however, could be causally contributing to declines in segregation in the metropolitan segregation, by locating affordable housing in tracts that then experience increased presence of whites. Because the emphasis of our paper is on the ultimate effect of segregation for metropolitan areas, not on neighborhood impacts per se, our work is more agnostic about causation at the neighborhood level.

\section{Empirical Analysis: Neighborhood Composition}

In this section, we empirically assess each of the dimensions raised (siting, tenant composition, and changes in neighborhood racial composition) in a series of partial assessments of LIHTC contributions to segregation via neighborhood composition. In each case, the assessment is incomplete, but sheds some light on the possible first-order program effects that could occur through a particular dimension of the LIHTC program.

\section{Data}

Our tract level characteristics are drawn from the Neighborhood Change Database, enabling us to link 1980 tract characteristics to 2000 tract definitions provided in the LIHTC database. Our primary data on metropolitan area characteristics come from the decennial census, in 1980, 1990, and 2000. Our data on LIHTC units placed in service come from HUD's Low Income Housing Tax Credit database, which describes the location of LIHTC units placed in service between 1987 and 2007. For this analysis 
we rely on a panel of 331 metropolitan areas, from 1980 through $2000 .^{24}$ (Eighty-four percent of tax credit developments are located in metropolitan areas). We limit our analysis to tax credit units built between 1987 and 1999. For three states, we have gathered data on the racial composition of tenants in LIHTC units, discussed in more detail below.

\section{Siting}

Following the approach taken in the existing literature on siting, we categorize tracts by their level of minority concentration, but in contrast to the existing literature we do so relative to that of all neighborhoods within an MSA. ${ }^{25}$ We first rank from lowest to highest all tracts in an MSA according to the share of their population that is minority, and divide these into quartiles. The bottom two quartiles of neighborhoods are combined and titled low (relative) minority concentration, tracts in the third quartile are classified as medium minority concentration and those above the $75^{\text {th }}$ percentile are labeled high minority concentration. These categories provide a sense of neighborhood minority concentration relative to those of other housing options in the same metropolitan area. To give a sense of context, fifty-three percent of minorities in metropolitan areas live in neighborhoods of high relative concentration, while less than 20 percent live in tracts classified as low concentration. ${ }^{26}$

[insert Table 1]

\footnotetext{
${ }^{24}$ We use 2000 MSA definitions and reconstruct the same MSAs for 1990 and 1980 using constant counties.

${ }^{25}$ An alternative approach is to compare exposure to minority populations for different housing groups, which we have also done with fairly similar results.

${ }^{26}$ These numbers are drawn from the 1990 Decennial Census, and include all minorities. The percent in high concentration neighborhoods is higher for African Americans.
} 
Table 1 presents the geographic distribution of LIHTC units by relative tract minority concentration. The first row provides the distribution of LIHTC units nationally, and the second provides a similar distribution of all housing units, for comparison. We can see that LIHTC units in metropolitan areas are almost twice as likely to be located in tracts with relatively high concentrations of minorities as are housing units overall -42.8 percent compared to 21.5 percent. Conversely, they are much less likely to be located in neighborhoods of low minority concentration. While just over half of all housing units are located in tracts of low minority concentration, only 29.7 percent of LIHTC units are located in such neighborhoods.

Table 1 also provides a breakout of LIHTC units by QCT, nonprofit, and central city status. Units in QCTs are considerably more skewed in their spatial distribution, with more than 80 percent located in tracts of high minority concentration. Nonprofit units and those in central cities are also more likely to be in tracts with high minority representation. $^{27}$

On the face of it, tax credit units are located in tracts which have relatively high concentrations of minorities within the MSA. However, whether the location of LIHTC developments contributes to higher or lower segregation depends in part on where tenants of those developments would otherwise be located (absent the LIHTC project). Tenants of such developments are low income renters, and where such households live also differs from the overall distribution of households, and varies by MSA.

\footnotetext{
${ }^{27}$ For brevity, Table 1 and 2 present results for units created during the 1990s (patterns are quite similar in other decades).
} 
To better capture our counterfactual - the racial composition of realistic alternative neighborhoods within the same MSA, we add to the existing research and consider two proxy groups who can be clearly identified in the census: renters who are poor (our best income cutoff among renters), and households with incomes below $150 \%$ of poverty (regardless of tenure status, which cannot be identified at this income cutoff in the Census). ${ }^{28}$ For each of these proxies, we determine the share of population (or units) ${ }^{29}$ living in each quartile, as we did for LIHTC units. We then compare the share of LIHTC units in each quartile to the share of each of these proxies in the same MSA in that quartile. A ratio above one indicates that the share of tax credit units in that quartile is greater than the share for our proxy group in that quartile, so tax credit units are more likely than the near poor or poor renters to be located in such neighborhoods. Table 2 presents these ratios by tract minority concentration, aggregated for all MSAs.

[insert Table 2]

The first three columns use the neighborhood distribution of the near poor as the counterfactual, those with poverty rates less than 150 percent of the poverty line. A drawback of this proxy is the inclusion of some homeowners, whose neighborhood options may differ from renters, in theory overestimating access to neighborhoods of lower minority concentration. The final three columns rely on the distribution of poor renters, potentially understating access to such neighborhoods by renters who meet the

\footnotetext{
${ }^{28}$ Within renters, Census data only identifies the poor versus non poor, which nationally has been estimated to approximate $30 \%$ of area median income (HUD, 2000). Given seventy-five percent of LIHTC tenants are estimated to have incomes below $50 \%$ of the area median income (GAO, 1997), we also consider a higher poverty cutoff ( 150 percent of poverty) for which tenure status cannot be distinguished.

${ }^{29}$ Where possible, our analysis relies on units: LIHTC units, overall housing units, rental units occupied by poor households. However, for measures of the near poor, this is calculated for the population as a whole, so we use the distribution of the population within the MSA.
} 
income requirements for LIHTC developments but whose incomes are a bit above the poverty line. In fact, the results are quite similar for the two approaches. We see that overall, tax credit units appear to have distributions across neighborhoods that are fairly similar to those of the near poor or poor renters in the same MSA, at least in terms of minority concentration, with slightly lower likelihood of being located in tracts of low minority concentration. ${ }^{30}$ Ignoring the racial composition of tenants (considered next), we might expect the siting of LIHTC units in a metropolitan area to have very little effect on segregation - tenants of such developments would otherwise live in neighborhoods with fairly similar minority concentrations, in contrast to what previous researchers have concluded and fair housing advocates expect. ${ }^{31}$

In terms of our subcategories, we do find that units built in QCTs, in central cities and those built by non profits, are still more likely to be developed in neighborhoods of high minority concentration. This greater likelihood, however, is much lower than the results presented in Table 1. Units in QCTs remain the most skewed, and are approximately twice as likely to be located in tracts of high minority concentration as are the near poor or poor renters. ${ }^{32}$ This could be interpreted as contributing to heightened segregation if we presume these developments themselves primarily house minorities.

\footnotetext{
${ }^{30} \mathrm{We}$ also calculated simple minority exposure rates for each of our groups (see Appendix A for formula). The average tax credit unit is in a neighborhood with .409 share minority. In those same MSAs, near poor are in tracts with .388 share minority, and poor renters, .365 . Creating similar ratios to take specific MSAs into account, on average, tax credit units have slightly higher exposure to minorities than do the near poor (7 percent higher) and poor renters (11 percent higher).

${ }^{31}$ Of course, to the extent that LIHTC tenants are more likely to be minority than poor renters or the near poor, these comparisons may overstate the ability of tenants to access lower minority neighborhoods via local housing markets.

${ }^{32}$ To the extent that there are existing barriers within MSAs on access to suburban housing for low income central city residents, the ratios we present may be biased upwards. Specifically, Table 1 and 2 contrasts the neighborhoods of central city LIHTC units to that of all near poor/ poor renters in the MSA. Tenant selection preferences could theoretically play a role in limiting access of central city residents to suburban developments.
} 


\section{Tenant Composition and Siting}

That tenants are primarily if not exclusively minority is the assumption made in much of the existing literature. Yet this need not be true. In theory at least, siting developments in tracts with a relatively high concentration of minorities might not contribute to higher levels of minority concentration in that tract if a smaller share of the tenants themselves are minority, ignoring other channels of impact.

To shed some light on this dimension of the LIHTC, we have acquired tenant racial composition data for LIHTC developments in metropolitan areas in three states, Delaware, Massachusetts and Texas. ${ }^{33}$ These states comprise a limited sample, but provide the first piece of suggestive evidence on the extent to which consideration of the racial composition of the developments themselves alters our expectations of the effect of siting LIHTC developments.

Table 3 presents summary data on these three states and the racial composition of tenants in LIHTC developments. ${ }^{34}$ The first column of each state panel provides the racial composition for tenants of LIHTC developments (first row) and the metropolitan populations in each state (second row). Tax credit developments do disproportionately (although not exclusively) house minorities. For each state, the minority share in

\footnotetext{
${ }^{33}$ While HUD has not required states to collect data on the race of tenants of tax credit projects, some states have collected these data for their own records. MA has a total of 27,423 tax credit (affordable) units, of which they have race data for $25,370(92.5 \%)$. There are also approximately 70 projects that were placed in service before 1990 for which they no longer collect data. We have racial data for $93 \%$ of developments in Texas and $96 \%$ in Delaware.

${ }^{34}$ For MA the reported data is based on the number of head of household minorities (all nonwhite heads of household) calculated as the share of all units for which race/ethnicity was reported. For Texas and Delaware, percent minority includes all households who are black or Hispanic.
} 
developments greatly exceeds the share of metropolitan population that is minority. In Massachusetts and Delaware, it exceeds the share of poor that is minority. ${ }^{35}$

[Insert Table 3]

Column 1 documents the large variation in the racial contexts of these states, with the share of the population that is minority in metropolitan areas in Massachusetts (18 percent), less than half that of Texas (49 percent). Looking across the columns, a greater presence of minorities in the general population is reflected in the racial composition of metropolitan tracts in these states (second row of each panel). Contrasting the states with smallest and largest metropolitan minority populations, high minority concentration tracts are 51 percent minority in Massachusetts compared to 84 percent minority in Texas. ${ }^{36}$ We can also see that LIHTC tenant composition varies with its surrounding neighborhood. Developments in areas with higher minority concentration themselves house more minorities.

To capture the effect of a particular development's racial composition on that of its surrounding neighborhood, we compare the percent of each development's tenants that are minority to that of the surrounding tract in row 3 of each panel. A ratio greater than one suggests that the presence of the development in that tract increases the tract's minority concentration (compositionally). Because the implication of this ratio for minority segregation overall varies by the neighborhood's minority concentration, columns 2-4 break out neighborhoods by low, medium and high minority concentration.

\footnotetext{
${ }^{35}$ The share of MSA poor that are minority is $44.3 \%$ in Massachusetts, $76.3 \%$ in Texas, and $56.3 \%$ in Delaware.

${ }^{36}$ These states also vary greatly in the share of minorities who live in tracts of high relative minority concentration, from a low of 40 percent of minorities in Texas to a high of 62 percent of minorities in Massachusetts.
} 
A ratio greater than one in neighborhoods of high minority concentration suggests increased segregation, while a ratio greater than one in neighborhoods of low minority concentration actually suggests decreased segregation.

Beginning with Massachusetts, these ratios do suggest that on average, LIHTC developments in all neighborhood classifications contribute to an increase in tract minority concentration. For the nearly two thirds of Massachusetts developments in tracts of high minority concentration, the share of tenants that is minority is 77 percent greater than in the surrounding neighborhood. Taking the racial composition of tenants into account does not change the first order expectation that locating developments in tracts of high minority concentration may contribute to heightened racial segregation (again, solely in terms of the receiving neighborhood's composition).

Texas, however, presents a counter case. In Texas, developments are much more evenly split between low, medium and high tracts. While the ratio of tenant minority composition to tract is greater than one for tracts with low and medium minority concentration, it falls to just about one (0.99) for tracts of high minority concentration. ${ }^{37}$ Purely in terms of the effect on those neighborhoods, such developments appear neutral in terms of minority concentration (ignoring where those residents would otherwise live, and any spillovers). Delaware falls in between. Based on evidence from these three states, we see that there does appear to be some variation in whether (and to what extent) locating a development in a neighborhood with a high concentration of minorities compositionally increases concentration of minorities in that tract.

\footnotetext{
${ }^{37}$ Indeed, given the ratio across all three neighborhood types, patterns in Texas might suggest LIHTC developments decrease racial segregation.
} 
Table 4 presents these data broken out by QCT, nonprofit and central city status of developments. Looking at the racial composition by development type (down column 1), developments in QCTs, central cities, and by nonprofit developers are all occupied by a greater share minority, although the differences in Texas are small. States vary greatly in their reliance on development types. Massachusetts relies much more heavily on nonprofit providers (almost half of its developments), and locates a much greater share of its developments in QCTs (more than half), than either of the other two states.

[Insert Table 4]

In terms of siting, Massachusetts and Texas continue to display two very different patterns. In Massachusetts, the overwhelming majority of central city, nonprofit and QCT tracts with tax credit units are located in high minority tracts. And in all cases, the average tax credit development in such tracts itself has greater representation of minorities among its tenants than the surrounding tract (1.47 in QCTs, 1.94 for nonprofits, and 1.73 in central city tracts). This pattern fits with the implicit assumptions of those criticizing such tax credit developments.

In Texas, we do not find this pattern. First, a sizable portion of developments in QCTs, by nonprofits and in central city tracts are located outside of tracts with high minority concentration. Almost 40 percent of LIHTC developments in QCTs, more than fifty percent of those developed by nonprofits, and almost fifty percent of those in central cities are located in tracts that have low or medium minority concentration. On average, developments in these tracts do have higher representation of minorities than the surrounding neighborhoods, at least potentially contributing to decreases in minority 
concentration, particularly since minorities appear to gain considerable access to these developments (on average they are approximately $70 \%$ minority). Second, for those developments that are in relatively high minority tracts, minority representation among tenants is about par with the neighborhood, and for QCTs, slightly lower than the neighborhood. As a first approximation, developments in high minority tracts do not appear to increase the concentration of minorities in these neighborhoods. And in

combination, developments in QCTs, by nonprofits or in central city tracts in Texas could lead to decreased segregation, at least through siting and tenant selection.

For Delaware, with patterns somewhere in between these two, developments in QCTs may also contribute to lower segregation. While almost all of Delaware QCT developments are located in tracts of high minority concentration, they house a smaller share minority than the surrounding tracts (.90). In this case, knowledge of the racial composition of tenants does affect expectations with respect to segregation.

These are limited case studies, and the variation across even these three states suggests simple generalization is not possible. However, what we do learn is that taking tenant composition into account can alter our priors on the expected outcomes of locating developments in high minority tracts, and the effects of units in QCTs, by nonprofits and in central cities on neighborhood racial composition and segregation.

\section{Changes in Neighborhood Composition}

Finally, it is also possible that once LIHTC developments are sited, the composition of who lives in the surrounding tract changes over time. Such changes may vary systematically across neighborhood and developer types. As such, focusing solely 
on the racial composition of a tract at the time the LIHTC is developed may provide an inaccurate picture of its effect on overall segregation. To assess the relationship between changes in neighborhood racial composition and newly sited LIHTC developments we estimate the following simple model of the change in the share of a neighborhood's population that is minority over the 1990-2000 decade:

$\Delta$ ShareMinority90-00 $=\alpha+\beta \Delta$ LIHTC90-99 $+\gamma \mathrm{X}_{\mathrm{n}}+\eta \mathrm{MSA}_{\mathrm{i}}+\varepsilon$

where $\mathrm{X}_{\mathrm{n}}$ is a vector of neighborhood level characteristics in 1990 (poverty, race and ethnic composition, other demographic and housing variables) ${ }^{38}$, and $\Delta$ LIHTC90-99 ${ }_{\mathrm{n}}$ is the total number of LIHTC units per capita placed in service in neighborhood $\mathrm{n}$ between 1990 and 1999. We model this variable in a number of different ways, splitting up units built in QCTs versus non QCTs, by nonprofits versus for profits, and in the central city versus suburb. We also include MSA fixed effects to help control for time-invariant metropolitan area characteristics. ${ }^{39}$

[Insert Table 5]

Table 5 summarizes our results for all tracts. We find that overall, locating a greater number of tax credit units per capita in a tract during the 1990s is associated with increasing levels of minority representation. Broken out by development type, however, there are systematic differences. A greater number of tax credit units located in QCTs is associated with declines in share minority, while units outside QCTs are associated with

\footnotetext{
${ }^{38}$ Table 5 contains the full list of controls.

${ }^{39}$ We have also used non linear measures of LIHTC units (quadratics, categorical variables for various sizes), and our main results hold.
} 
increases. Units in central city tracts, those in the suburbs, and those developed by for profits, are associated with increases in minority share. As already noted, however, whether such changes in minority concentration are expected to contribute to an increase or decrease in overall segregation depends on the initial level of minority representation in the neighborhood. Table 6 presents results when we estimate this model separately for neighborhoods that began the decade with relatively low, medium and high levels of minority concentration.

[Insert Table 6]

Focusing first on tracts that began the decade with low minority concentration and tax credit units overall (column 1), greater per capita units are associated with increases in share minority in the tract. For tracts of medium minority concentration (column 5), the coefficient on per capita tax credit units is still positive and significant but of a much smaller magnitude. For tracts of high minority concentration (column 9), there is no significant relationship overall between LIHTC units and changes in minority concentration. The significant positive effect found in Table 5 holds most strongly for neighborhoods which began the decade with low concentrations of minorities, a pattern that is more consistent with the siting of LIHTC developments actually contributing to declines in segregation. It is worth pointing out that the composition of minorities might be changing. For example, in models (results not shown) that disaggregate minority groups, greater per capita LIHTC units in a tract may be associated with an increase in share African American and a decline in share Hispanic. 
In terms of particular uses of the tax credit, the pattern across neighborhood types in coefficients on per capita LIHTC units in QCTs (and those produced by nonprofits) is even more consistent with declines in concentration, rather than increases. The only significant coefficient on units in QCTs is negative, for tracts that began the decade with high minority concentration. For units built by nonprofits, the coefficient is significant and positive in tracts that began the decade with low minority concentration and significant and negative in neighborhoods of high minority concentration. This also highlights that, contradicting the expectations of fair housing advocates, while the initial siting of tax credit units in such tracts of high minority concentration may appear to contribute to greater segregation, changes in such tracts' composition over time may have the opposite effect.

Of course, there are several reasons the racial composition might change in tracts where developments are built. The development itself has tenants, and as just examined in Delaware, Massachusetts and Texas, the racial composition of the tenants themselves may vary by and affect tract minority concentration (compositional effect). In addition, developers may be selecting tracts that while being highly racially concentrated at the start of the decade, are going to experience declines in minority concentration (selection). Finally, there may be spillover effects on the neighborhood choices of non development residents of the tract. Our model as estimated cannot distinguish between these effects, and each of these is relevant for overall MSA segregation. As noted previously, our interest is not in determining a causal relationship between developments and racial composition at the neighborhood level, but rather how such siting and subsequent changes (however caused) affect overall segregation. 
We can, however, conduct some additional analysis that eliminates the compositional effect of the tax credit program, which is at least suggestive of possible channels. If tenant composition were the entire story, then the change in racial composition of a tract would be limited to development tenants, who are renters. To remove this compositional effect, we estimate similar models of change in racial composition of homeowners in each tract. We find an even stronger pattern between the presence of LIHTC projects and declines in minority concentration. High minority concentration tracts that receive LIHTC units experience a decline in minority homeowners, while low minority concentration tracts experience the reverse pattern (with generally no significant effects in tracts of medium minority concentration). Our earlier results do not appear driven solely by compositional changes due to the presence of LIHTC tenants themselves.

Alternatively these changes could arise from the siting of tax credit units in tracts that are going to change this way anyway (and thereby locating subsidized households in tracts that are becoming less concentrated.) To help control for selection, we also estimate our models using only tracts that experience some LIHTC development during the decade, contrasting tracts with a greater number of LIHTC units to those with fewer. The results are very similar. As a further control on such selection, we re-estimate our models controlling not only for share minority at the start of the decade, but trends over the previous decade. Controlling for such trends does not change our results.

We also examined selection directly, estimating a model of the probability that a tract will receive a tax credit development during the 1990s, given the change in minority composition in the previous decade, and controlling for a number of other factors that 
could affect the probability a tract receives a tax credit. ${ }^{40}$ Stratified by minority concentration in 1990, we find that the high minority concentration neighborhoods selected for development were more likely to have experienced increases in minority concentration in the previous decade, so the subsequent decline in minority concentration is a reversal of trend.

Of course, it is still possible that developers are selecting neighborhoods whose racial patterns are going to change in ways not reflected by prior patterns but observable to those 'on the ground.' Regardless of the causal mechanism, the patterns suggest that changes in neighborhood racial composition over time may counter prima facia expectations about the effect of locating developments in high minority neighborhoods based solely on the initial composition of the neighborhood.

In sum, our evidence on the ways through which LIHTC developments may affect segregation generally do not support concern of heightened segregation, even for those located in QCTs. Moreover, when several channels are considered, it is unclear whether on net, LIHTC developments might not actually decrease overall segregation.

\section{Empirical Analysis: Net MSA effects}

As noted, it is the net effect of all channels that matter for segregation, so we now consider this directly, through simple models of MSA level segregation. Our key interest is the ultimate impact of the tax credit units on racial segregation patterns at the metropolitan level. If tax credit developments do alter the spatial distribution of households and ultimately racial segregation, we expect this effect to be largest in areas in which a greater share of the population resides in such developments. To address this

\footnotetext{
${ }^{40}$ Results available from the authors.
} 
question, we take advantage of the variation in prevalence of LIHTC developments across metropolitan areas and across time. While tax credits are allocated to states on a per capita basis, the distribution within states varies tremendously. In 2000, while the average MSA had 305 tax credit units per 100,000, people, this varied from a low of 0 to a high of 890 . In 1990, the average MSA had only 55 tax credit units per 100,000.

We employ two measures of segregation widely used in the literature, the dissimilarity and isolation indices. While correlated, each captures a somewhat different dimension of segregation. ${ }^{41}$ Each index varies from 0 (no segregation/isolation) to 1 (complete segregation/isolation). ${ }^{42}$ We estimate a series of panel models of MSA segregation from 1980 to 2000 , as follows:

$\operatorname{RacSeg}_{i t}=\alpha+\beta \mathrm{X}_{\mathrm{it}}+\gamma \mathrm{LIHTC}_{\mathrm{it}}+\eta \mathrm{MSA}_{\mathrm{i}}+\theta \mathrm{YEAR}_{\mathrm{t}}+\varepsilon$

where $\mathrm{X}_{\mathrm{it}}$ is a vector of metropolitan level characteristics described below, and LIHTC is the total number of LIHTC units per capita as of year $t$ in $\mathrm{MSA}_{\mathrm{i}}$. As in our previous models, LIHTC is modeled in a number of different ways. We also estimate models with MSA fixed effects to capture non varying aspects of MSAs that may jointly affect segregation and the use of the LIHTC program, and year dummies.

We also include a number of metropolitan controls that may vary over time and which are consistently cited in the literature surrounding the causes of racial segregation. We include demographic characteristics of metropolitan areas, including population, share minority, share foreign born, poverty rate, age distribution and education (Cutler,

\footnotetext{
${ }^{41}$ For overviews of the issues and measures see Taeuber and Taeuber, 1965; James and Taeuber, 1985; Reardon and Firebaugh, 2002.

${ }^{42}$ Appendix A describes these measures in more detail, including their mathematical calculation.
} 
Glaeser and Vigdor, 1999; Bayer, McMillan and Reuben, 2004; Farley and Frey, 1994.)

Finally we include a number of characteristics describing the metropolitan housing stock, such as the percent of the housing stock built within the past 5 years (Farley and Frey, 1994), and the homeownership rate in an MSA (Ellen, 2000).

A concern with our empirical strategy is that the presence of LIHTC developments in an MSA is not random. States (or developers in their decision to apply for credits) select metropolitan areas on the basis of numerous characteristics, some that may also affect segregation. For example, some states establish set asides or priorities for areas of greater population size. Many states prioritize areas of greater housing need, both for affordable housing and for tight housing markets (low vacancy rates). ${ }^{43}$

Developers may be most attracted to metropolitan areas that are growing, and have higher average rents. Some of these factors may also affect levels (or changes) in segregation.

We attempt to address the selection issue by controlling for observable characteristics of metropolitan areas that may matter for selection, such as MSA size, demographics of the population, and housing characteristics (including vacancy rates and median housing value). ${ }^{44}$ We also include MSA fixed effects, which controls for time invariant MSA characteristics that may matter for both segregation and selection.

Finally, as an additional control on time varying factors that may be correlated with the use of LIHTC units and the spatial distribution of households, we include measures of the availability of other subsidized housing, particularly public housing and Hope VI projects.

\footnotetext{
${ }^{43}$ Various state QAPs available on line.

${ }^{44}$ The most direct method for dealing with such selection would be to identify an instrument, something which varies with the prevalence of LIHTC units but does not otherwise affect segregation. While we have considered several instrument strategies based on population and housing market factors, such factors would also directly affect segregation and we do not believe they make credible instruments.
} 
Results

Table 7 summarizes our results for these models. The first three columns use the minority dissimilarity index to measure segregation, and the final three use minority isolation. In terms of control variables, once MSA fixed effects are included in the models, many MSA demographic variables are insignificant. Several housing variables remain significant, such as share of housing built in the previous five years and percent homeowners (both of which are negative), and vacancy rates (positive). While the total number of public housing units is not significant (and does not vary much within MSA across time), the presence of HOPE IV projects is significant. MSAs with such projects experienced declines in segregation during this time period. ${ }^{45}$

[Insert Table 7]

Focusing on LIHTC units, columns (1) and (5) reveal significantly negative coefficients on LIHTC units per capita, overall. Metropolitan areas that experienced increases in tax credit units experienced declines in segregation. Focusing on the uses of greatest interest, we do not find any evidence that even these uses of tax credits contribute to heightened segregation. Indeed, in both models, we have significantly negative coefficients on per capita LIHTC units in QCTs, and the magnitude of these coefficients is much greater than for LIHTC units overall. For units developed by nonprofits and those located in central city tracts, the coefficients are always negative,

\footnotetext{
${ }^{45}$ When we model HOPE VI dollars, rather than as a dummy variable, it is no longer significant. We may well be capturing something important about areas selected for HOPE VI (and other correlated projects). rather than new developments per se. For our purposes, as a control for otherwise unobservable changes in housing markets and policy, we prefer the dummy variable.
} 
and in one model significant. We have also run these models focusing on black/white segregation, and Hispanic/white, and get essentially the same results: changes in development of LIHTC units per capita are significantly associated with declines in MSA segregation, with the strongest and most consistent results found for those located in QCTs. ${ }^{46}$

We have also run several additional robustness tests. Since tax credit developments that are funded with tax exempt bonds typically automatically qualify for a four percent tax credit rather than the capped and competitive standard nine percent credit, we also ran our models excluding these developments. Our results do not change. Nor do they change when we eliminate developments specifically targeting the elderly (which may differ both in tenant composition and siting). When we model new construction versus rehabilitation, in a variety of manners, there is again no evidence of a positive relationship, and a significant negative relationship is maintained for rehab units. $^{47}$

While significant, the magnitude of these effects at first may appear small. For example, if we increase the number of tax credit units in an MSA (population of 100,000) in the 1990s by one standard deviation (187 additional units, or 0.00187 per capita), the dissimilarity index is predicted to be .01 lower (the average dissimilarity index in 1990 was .451). However, segregation measures change very little over time. Between 1990

\footnotetext{
${ }^{46}$ While all relevant coefficients are negative in all models, they are not uniformly significant. See Appendix B for full results.

${ }^{47}$ Though we may expect rehab to have a weaker relationship with neighborhood racial composition than new construction as these developments are more likely to prioritize previous tenants, these results could potentially be driven by spillover effects of LIHTC rehab developments. Rehab developments may be improving particularly dilapidated old buildings and in this way could have an even stronger impact on neighborhood racial change. Given our current data we cannot test these hypotheses, so this is purely speculative. These impacts could also vary by type of development undertaken and location, but again we cannot identify this with the current data.
} 
and 2000 the average MSA experienced a decline in dissimilarity of .023. Given that the average MSA placed 305 tax credit units per 100,000 in service during the 1990s, our model predicts the average MSA should experience a decline of 0.016 in segregation only slightly lower than the decline in dissimilarity actually experienced on average. In terms of changes in segregation, the coefficients suggest the actual increases in the LIHTC program in the 1990s could have played a sizable role in the small changes in segregation that were actually experienced.

\section{Conclusion}

In summary, we find no evidence that the LIHTC program is associated on average with greater racial segregation for minorities. Indeed, MSAs with greater construction of LIHTC units experience relative declines in segregation. Focusing on those units which may have the greatest potential for heightening segregation, we again find essentially no evidence to support this concern, but rather, evidence of the reverse. Our empirical examination of three potential mechanisms through which the LIHTC could affect segregation is generally consistent with these mechanisms being primarily neutral or even lowering segregation.

Compared to where tenants would otherwise live in the same MSA, the siting of developments overall generally are not in tracts of greater relative concentration of minorities, although some uses of tax credits (in QCTs, in the central city, and by nonprofits) are in such tracts. While only illustrative, data from three states suggest that in some cases, taking the racial composition of tenants into account matters for interpreting the possible effect of siting on a neighborhood's racial composition. In two 
of these three states, developments in QCTS that are in high minority tracts house tenants who are either identical to the neighborhood composition or slightly less likely to be minority than the surrounding residents. Nationally, two thirds of developments are located outside of such tracts, where the racial composition of tenants suggests they may contribute to lower segregation. And in terms of changes over time, our models of neighborhood racial change suggest that on average, the development of LIHTC units in a tract is associated with neighborhood changes that may contribute to lower levels of segregation at the MSA level. These each suggest plausible reasons why MSA segregation might not increase, and might even decrease with use of LIHTC housing. This work also highlights that focusing solely on the racial composition of neighborhoods at initial siting, or national patterns of siting with no assessment of who tenants are or where they might otherwise live may not provide an accurate picture of the possible effect of LIHTC developments on segregation.

There are some important caveats on our findings. Though on average we do not find that LIHTC units are associated with increased levels of racial segregation, this does not signify that all developments are benign. It is still quite possible that advocates are correct, that in some cases tax credit developments do increase patterns of racial segregation. However, our analysis suggests this scenario would be the exception and not the rule.

We can also be criticized for applying too low a hurdle in this analysis. That the LIHTC program as currently implemented appears to 'do no harm' in terms of racial segregation (and possibly a small amount of 'good') suggests that it may be no worse than are our housing markets and other housing programs in terms of segregation. Given 
our history of persistently high levels of racial segregation in this country, a strong argument could be made that we might require more of our federal housing efforts. Indeed, affirmatively furthering fair housing goals may require programs to contribute affirmatively to sizable improvements in the existing high levels of segregation. That said, focusing criticism of the LIHTC on such components as siting in QCTs due to concerns of racial concentration rather than other neighborhood characteristics (such as school quality or access to employment) or other program attributes (who is actually served) may miss more important avenues for improving this housing program. 


\section{References:}

Baum-Snow, Nathan, and Justin Marion. 2009. "The Effects of Low Income Housing Tax Credit Developments on Neighborhoods." Journal of Public Economics 93: 654-666.

Bayer, Patrick, Robert McMillan, and Kim S. Reuben. 2004. "What Drives Racial Segregation? New Evidence Using Census Microdata." Journal of Urban Economics 56: 514-535.

Buron, Larry, Sandra Nolden, Kathleen Heintz, and Julie Stewart. 2000. Assessment of the Economic and Social Characteristics of LIHTC Residents and Neighborhoods. Cambridge, MA: Abt Associates Inc.

Cutler, David M., Edward L. Glaeser, and Jacob L. Vigdor. 1999. "The Rise and Decline of the American Ghetto.” Journal of Political Economy 107: 455-506.

Deng, Lan. 2007. "Comparing the Effects of Housing Vouchers and Low-Income Housing Tax Credits on Neighborhood Integration and School Quality.” Journal of Planning Education and Research 27: 20-35.

Ellen, Ingrid Gould. 2000. Sharing America's Neighborhoods: The Changing Prospects for Stable, Racial Integration. Cambridge, MA: Harvard University Press.

Ellen, Ingrid Gould, Katherine O'Regan, and Ioan Voicu. 2008. "Siting, Spillovers, and Segregation: A Reexamination of the Low Income Housing Tax Credit Program." In Housing Markets and the Economy: Risk, Regulation, and Policy, edited by Edward L. Glaeser and John M. Quigley, 233-267. Cambridge, MA: Lincoln Institute of Land Policy.

Eriksen, Michael D., and Stuart S. Rosenthal. 2007. "Crowd Out, Stigma and the Effect of Place-Based Subsidized Rental Housing." University of Syracuse, Working Paper.

Farley, Reynolds, and William H. Frey. 1994. "Changes in the Segregation of Whites from Blacks during the 1980s: Small Steps toward a More Integrated Society." American Sociological Review 59: 23-45.

Freeman, Lance. 2004. Siting Affordable Housing: Location and Neighborhood Trends of Low Income Housing Tax Credit Developments in the 1990s. The Brookings Institution Census 2000 Survey Series: 1-18.

Freeman, Lance and William Rohe. 2000. "Subsidized housing and neighborhood racial transition: An empirical investigation." Housing Policy Debate 11(1): 67-89. 
Funderburg, Richard, and Heather MacDonald. 2010. "Neighbourhood Valuation Effects from New Construction of Low-Income Housing Tax Credit Projects in Iowa: A Natural Experiment." Urban Studies 47: 1745-1771.

Goering, John. 2005. "Expanding Housing Choice and Integrating Neighborhoods: The MTO Experiment." In The Geography of Opportunity: Race and Housing Choice in Metropolitan America, edited by Xavier de Souza Briggs, 127-49. Washington, DC: Brookings Institution Press.

Green, Richard K., Stephen Malpezzi, Kiat-Ying Seah. 2002. Low Income Housing Tax Credit Housing Developments and Property Values. University of Wisconsin, The Center for Urban Land Economics Research.

James, David R. and Karl E. Taeuber. 1985. "Measures of Segregation," Sociological Methodology 15 (1985): 1-32.

McClure, Kirk. 2006. "The Low-Income Housing Tax Credit Program Goes Mainstream and Moves to the Suburbs." Housing Policy Debate 17: 419-446.

Olsen, Edgar O. 2003. "Housing programs for low income households." In Means Tested Transfer Programs in the U.S., edited by Robert A. Moffitt 365-442, Chicago: University of Chicago Press.

Orfield, Myron. 2005. "Racial Integration and Community Revitalization: Applying the Fair Housing Act to the Low Income Housing Tax Credit." Vanderbilt Law Review 58: 1747-1804.

Poverty and Race Research Action Council (PRRAC). 2004. Civil Rights Mandates in the Low Income Housing Tax Credit Program. http://www.prrac.org/pdf/crmandates.pdf

Reardon, Sean F. and Glenn Firebaugh. 2002. "Measures of Multigroup Segregation." Sociological Methodology 32: 33-67.

Schwartz, Amy Ellen, Ioan Voicu, Michael Schill. 2006. "The External Effects of Subsidized Housing Investment." Regional Science and Urban Economics 36: 697-707.

Shah, Seema R. 2005. "Having Low Income Housing Tax Credit Allocation Plans Take into Account the Quality of Schools at Proposed Family Housing Sites: A Partial Answer to the Residential Segregation Dilemma?" Indiana Law Review 39: 691718.

Taeuber, Karl E., and Alma F. Taeuber.1965. Negroes in Cities: Residential Segregation and Neighborhood Change. Chicago: Aldine Publishing Co. 
U.S. General Accounting Office. 1997. Tax Credits Opportunities to Improve Oversight of the Low-Income Housing Program. U.S. General Accounting Office.

U.S. Housing and Urban Development. 2000. Rental Housing Assistance - The Worsening Crisis: Report to Congress on Worst Case Housing Needs. Office of Policy Development and Research. 
Table 1 Siting of Low Income Housing Tax Credit Projects

\begin{tabular}{|l|c|c|c|}
\hline \multirow{2}{*}{} & \multicolumn{2}{|c|}{ Percent of Units built in tracts with minority concentration that is: } \\
\cline { 2 - 4 } US Total: & & Medium & High \\
LIHTC Units & $29.7 \%$ & & \\
All Housing Units & $52.4 \%$ & $27.6 \%$ & $42.8 \%$ \\
Ratio LIHTC/All & 0.57 & $26.1 \%$ & $21.5 \%$ \\
& & 1.06 & 1.99 \\
LIHTC Units: & & & \\
In QCTs (30\% of units) & $2.2 \%$ & $13.8 \%$ & $84.0 \%$ \\
Outside QCTs (70\%) & $40.3 \%$ & $32.9 \%$ & $26.8 \%$ \\
& & & \\
Not for Profits (25\% of units) & $22.2 \%$ & $23.8 \%$ & $54.0 \%$ \\
For Profits (75\%) & $31.2 \%$ & $28.8 \%$ & $40.0 \%$ \\
& & & \\
Central City (57\% of units) & $15.3 \%$ & $24.4 \%$ & $60.3 \%$ \\
Suburbs (43\%) & $47.0 \%$ & $28.9 \%$ & $24.1 \%$ \\
\hline
\end{tabular}

Low: Relative Minority Concentration under 50th Percentile in MSA

Medium: Relative Minority Concentration 50-75 Percentile in MSA

High: Relative Minority Concentration Over 75th Percentile in MSA 
Table 2 Siting of Low Income Housing Tax Credit Projects

\begin{tabular}{|c|c|c|c|c|c|c|}
\hline & \multicolumn{3}{|c|}{$\begin{array}{l}\% \text { of LIHTC Units / \% of Near Poor Population } \\
\text { in tracts with minority concentration that is: }\end{array}$} & \multicolumn{3}{|c|}{$\begin{array}{l}\% \text { of LIHTC Units / \% of Poor Renter Households } \\
\text { in tracts with minority concentration that is: }\end{array}$} \\
\hline & Low & Medium & High & Low & Medium & High \\
\hline US Total & 0.90 & 1.07 & 1.03 & 0.97 & 0.96 & 1.05 \\
\hline LIHTC Units: & & & & & & \\
\hline In QCTs & 0.07 & 0.54 & 2.03 & 0.07 & 0.48 & 2.06 \\
\hline Not in QCTs & 1.23 & 1.28 & 0.65 & 1.32 & 1.15 & 0.66 \\
\hline Not for Profits & 0.68 & 0.92 & 1.31 & 0.73 & 0.83 & 1.33 \\
\hline For Profits & 0.95 & 1.12 & 0.97 & 1.02 & 1.01 & 0.98 \\
\hline Central City & 0.46 & 0.95 & 1.46 & 0.50 & 0.85 & 1.48 \\
\hline Suburbs & 1.43 & 1.12 & 0.58 & 1.54 & 1.01 & 0.59 \\
\hline
\end{tabular}

Low: Relative Minority Concentration under 50th Percentile in MSA Medium: Relative Minority Concentration 50-75 Percentile in MSA High: Relative Minority Concentration over 75th Percentile in MSA 
Table 3 Share Minority in Tax Credit Developments and Surrounding Tracts

\begin{tabular}{|c|c|c|c|c|}
\hline & \multirow[b]{2}{*}{$\begin{array}{l}\text { All Tracts } \\
\text { (1) }\end{array}$} & \multicolumn{3}{|c|}{ Relative Minority Concentration } \\
\hline & & $\begin{array}{l}\text { Low } \\
(2)\end{array}$ & $\begin{array}{l}\text { Medium } \\
\text { (3) }\end{array}$ & $\begin{array}{l}\text { High } \\
(4)\end{array}$ \\
\hline \multicolumn{5}{|l|}{ Massachusetts } \\
\hline $\begin{array}{l}\text { Percent Minority : } \\
\quad-\text { - in LIHTC developments }\end{array}$ & $65.2 \%$ & $31.9 \%$ & $44.5 \%$ & $77.4 \%$ \\
\hline -- in population & $17.8 \%$ & $4.8 \%$ & $16.2 \%$ & $51.0 \%$ \\
\hline Ratio: development/tract & 3.99 & 13.91 & 4.25 & 1.77 \\
\hline Number of developments & 327 & 54 & 64 & 209 \\
\hline \multicolumn{5}{|l|}{ Texas } \\
\hline \multicolumn{5}{|l|}{ Percent Minority : } \\
\hline -- in LIHTC developments & $72.5 \%$ & $57.3 \%$ & $73.2 \%$ & $80.8 \%$ \\
\hline -- in population & $49.0 \%$ & $28.4 \%$ & $58.7 \%$ & $84.4 \%$ \\
\hline Ratio: development/tract & 1.47 & 2.29 & 1.47 & 0.99 \\
\hline Number of developments & 1074 & 291 & 367 & 416 \\
\hline \multicolumn{5}{|l|}{ Delaware } \\
\hline \multicolumn{5}{|l|}{ Percent Minority : } \\
\hline -- in LIHTC developments & $59.6 \%$ & $39.8 \%$ & $50.6 \%$ & $67.6 \%$ \\
\hline -- in population & $30.0 \%$ & $11.9 \%$ & $26.3 \%$ & $58.5 \%$ \\
\hline Ratio: development/tract & 1.66 & 3.21 & 1.88 & 1.22 \\
\hline Number of developments & 62 & 12 & 15 & 35 \\
\hline
\end{tabular}


Table 4 Ratio of Share Minority in Tax Credit Developments to Surrounding Tracts, by QCT, Nonprofit and Central City

\begin{tabular}{|c|c|c|c|c|c|c|c|c|}
\hline & & & \multicolumn{6}{|c|}{ Tracts by Relative Minority Concentration } \\
\hline & \multicolumn{2}{|c|}{ All Tracts } & \multicolumn{2}{|c|}{ Low } & \multicolumn{2}{|c|}{ Medium } & \multicolumn{2}{|c|}{ High } \\
\hline & $\begin{array}{l}\text { \% Min } \\
\text { Dev }\end{array}$ & Num Dev & $\begin{array}{l}\% \text { Min Dev/ } \\
\% \text { Min Trct }\end{array}$ & Num Dev & $\begin{array}{l}\% \text { Min Dev/ } \\
\% \text { Min Trct }\end{array}$ & Num Dev & $\begin{array}{l}\% \text { Min Dev/ } \\
\% \text { Min Trct }\end{array}$ & Num Dev \\
\hline \multicolumn{9}{|l|}{ Massachusetts } \\
\hline QCT & $75.6 \%$ & 189 & -- & & 3.56 & 19 & 1.47 & 166 \\
\hline Non QCT & $50.8 \%$ & 138 & 9.48 & 50 & 4.53 & 45 & 2.71 & 43 \\
\hline Non Profit Developers & $71.1 \%$ & 143 & 6.87 & 13 & 4.61 & 29 & 1.94 & 101 \\
\hline For Profit Developers & $61.2 \%$ & 146 & 14.89 & 36 & 4.18 & 30 & 1.69 & 80 \\
\hline Central City & $75.6 \%$ & 224 & 25.49 & 13 & 5.00 & 34 & 1.73 & 177 \\
\hline Non Central City & $32.2 \%$ & 103 & 9.68 & 41 & 3.40 & 30 & 2.23 & 32 \\
\hline \multicolumn{9}{|l|}{ Texas } \\
\hline QCT & $74.0 \%$ & 386 & 1.41 & 9 & 1.26 & 135 & 0.94 & 242 \\
\hline Non QCT & $71.6 \%$ & 688 & 2.31 & 282 & 1.59 & 232 & 1.05 & 174 \\
\hline Non Profit Developers & $76.1 \%$ & 63 & 2.75 & 14 & 1.79 & 20 & 0.99 & 29 \\
\hline For Profit Developers & $74.0 \%$ & 472 & 2.28 & 119 & 1.47 & 150 & 0.99 & 203 \\
\hline Central City & $77.2 \%$ & 659 & 2.22 & 78 & 1.46 & 233 & 1.00 & 348 \\
\hline Non Central City & $63.3 \%$ & 415 & 2.31 & 213 & 1.50 & 134 & 0.91 & 68 \\
\hline \multicolumn{9}{|l|}{ Delaware } \\
\hline QCT & $77.7 \%$ & 12 & -- & & -- & & 0.90 & 11 \\
\hline Non QCT & $55.9 \%$ & 50 & 2.85 & 11 & 1.88 & 15 & 1.32 & 24 \\
\hline Non Profit Developers & $76.1 \%$ & 16 & -- & & -- & & 1.29 & 13 \\
\hline For Profit Developers & $55.3 \%$ & 46 & 3.26 & 10 & 1.86 & 14 & 1.19 & 22 \\
\hline Central City & $78.0 \%$ & 27 & -- & & -- & & 1.28 & 22 \\
\hline Non Central City & $45.6 \%$ & 35 & 2.35 & 9 & 1.79 & 13 & 1.14 & 13 \\
\hline
\end{tabular}

Observations with fewer than five developments are omitted 
Table 5 Changes in Share of Tract Population that is Minority

\begin{tabular}{|c|c|c|c|c|}
\hline & \multicolumn{4}{|c|}{ All Neighborhoods } \\
\hline \multirow{3}{*}{$\Delta$ Per Capita (PC) Units } & (1) & $(2)$ & (3) & (4) \\
\hline & $0.118^{\star \star *}$ & & & \\
\hline & 0.02 & & & \\
\hline$\triangle Q C T$ PC Units & & $-0.200^{* * *}$ & & \\
\hline \multirow[t]{2}{*}{$\triangle$ Non QCT PC Units } & & $\begin{array}{l}0.033 \\
0.295^{\star \star \star}\end{array}$ & & \\
\hline & & 0.025 & 0.000 & \\
\hline$\Delta$ Non Profit Units & & & 0.054 & \\
\hline$\Delta$ For Profit Units & & & $0.205^{\star * *}$ & \\
\hline$\Delta$ Cent City PC Units & & & 0.025 & $0.062^{* * *}$ \\
\hline$\triangle$ Suburban PC Units & & & & $\begin{array}{l}0.024 \\
0.245^{\star \star *}\end{array}$ \\
\hline \multirow[t]{2}{*}{ Log Tract Pop } & $0.008^{\star \star \star}$ & $0.008^{* \star *}$ & $0.008^{\star \star \star}$ & $\begin{array}{l}0.036 \\
0.008^{\star \star \star}\end{array}$ \\
\hline & 0.001 & 0.001 & 0.001 & 0.001 \\
\hline$\%$ Black & $\begin{array}{l}-0.060^{* * *} \\
0.002\end{array}$ & $\begin{array}{l}-0.060^{\star \star \star} \\
0.002\end{array}$ & $\begin{array}{l}-0.060^{\star \star *} \\
0.002\end{array}$ & $\begin{array}{l}-0.060^{\star * *} \\
0.002\end{array}$ \\
\hline \multirow[t]{2}{*}{$\%$ Hispanic } & $-0.088^{* * *}$ & $-0.089^{\star * *}$ & $-0.088^{* * *}$ & $-0.088^{* * *}$ \\
\hline & $\begin{array}{l}0.004 \\
0.066^{* * *}\end{array}$ & $\begin{array}{l}0.004 \\
0.067^{\star \star \star}\end{array}$ & $\begin{array}{l}0.004 \\
0.066^{\star * *}\end{array}$ & $\begin{array}{l}0.004 \\
0.066^{\star * *}\end{array}$ \\
\hline$\%$ Foreign Born & 0.007 & 0.007 & 0.007 & 0.007 \\
\hline \multirow[t]{2}{*}{$\%$ College Degree } & $-0.127^{\star \star \star}$ & $-0.127^{\star \star \star}$ & $-0.127^{\star \star \star}$ & $-0.126^{\star \star \star}$ \\
\hline & $\begin{array}{l}0.003 \\
-0.189^{* * *}\end{array}$ & $\begin{array}{l}0.003 \\
-0.181^{* * *}\end{array}$ & $\begin{array}{l}0.003 \\
-0.188^{* * *}\end{array}$ & $\begin{array}{l}0.003 \\
-0.188^{* * *}\end{array}$ \\
\hline$\%$ Poor & $\begin{array}{l}-0.189^{\text {** }} \\
0.006\end{array}$ & $\begin{array}{l}-0.181^{\star \star \star} \\
0.006\end{array}$ & $\begin{array}{l}-0.188^{\star \star \star} \\
0.006\end{array}$ & $\begin{array}{l}-0.188^{\star \star \star} \\
0.006\end{array}$ \\
\hline \multirow[t]{2}{*}{$\%$ Home Owners } & $-0.122^{\star \star *}$ & $-0.122^{* * *}$ & $-0.122^{* * *}$ & $-0.122^{* * *}$ \\
\hline & 0.003 & 0.003 & 0.003 & 0.003 \\
\hline \multirow[t]{2}{*}{ \% Built post 1995} & $-0.023^{\star * \star}$ & $-0.024^{\star * *}$ & $-0.023^{\star \star \star}$ & $-0.023^{\star \star \star}$ \\
\hline & 0.004 & 0.004 & 0.004 & 0.004 \\
\hline \multirow[t]{2}{*}{$\%$ Built pre 1960} & 0.000 & 0.000 & 0.000 & 0.000 \\
\hline & 0.002 & 0.002 & 0.002 & 0.002 \\
\hline \multirow[t]{2}{*}{ Constant } & $0.154^{* * *}$ & $0.155^{\star \star \star}$ & $0.153^{* * *}$ & $0.154^{* * *}$ \\
\hline & 0.007 & 0.007 & 0.007 & 0.007 \\
\hline MSA FE & $\mathrm{x}$ & $\mathrm{x}$ & $x$ & $x$ \\
\hline $\mathrm{N}$ & 50001 & 50001 & 50001 & 50001 \\
\hline
\end{tabular}

standard errors below coefficients

${ }^{*} p<.1,{ }^{* *} p<.05,{ }^{* * *} p<.01$ 
Table 6 Changes in Share of Tract Population that is Minority, by tract relative minority concentration

\begin{tabular}{|c|c|c|c|c|c|c|c|c|c|c|c|c|}
\hline \multirow{2}{*}{$\Delta$ Per Capita (PC) Units } & \multicolumn{4}{|c|}{ Low Minority Concentration } & \multicolumn{4}{|c|}{ Medium Minority Concentration } & \multicolumn{4}{|c|}{ High Minority Concentration } \\
\hline & $\begin{array}{c}(1) \\
0265^{* * *}\end{array}$ & (2) & (3) & (4) & $\begin{array}{c}(5) \\
0170^{* * *}\end{array}$ & (6) & $(7)$ & (8) & $\begin{array}{c}(9) \\
0015\end{array}$ & $(10)$ & $(11)$ & (12) \\
\hline & 0.028 & & & & 0.046 & & & & 0.028 & & & \\
\hline$\triangle Q C T$ PC Units & & 0.193 & & & & 0.102 & & & & $-0.133^{\star * \star}$ & & \\
\hline & & 0.139 & & & & 0.085 & & & & 0.035 & & \\
\hline$\triangle$ Non QCT PC Units & & $\begin{array}{l}0.268^{* * *} \\
0.029\end{array}$ & & & & $\begin{array}{l}0.197^{\star * *} \\
0.054\end{array}$ & & & & $\begin{array}{l}0.229^{* * *} \\
0.042\end{array}$ & & \\
\hline$\Delta$ Non Profit Units & & & $0.409^{* *}$ & & & & 0.181 & & & & $-0.144^{* *}$ & \\
\hline$\Delta$ For Profit Units & & & $\begin{array}{l}0.089 \\
0.280^{\star *}\end{array}$ & & & & $\begin{array}{l}0.151 \\
0.200^{* *}\end{array}$ & & & & $\begin{array}{l}0.064 \\
0.109^{\star * *}\end{array}$ & \\
\hline & & & 0.033 & & & & 0.053 & & & & 0.037 & \\
\hline$\Delta$ Cent City PC Units & & & & $0.315^{\star \star \star}$ & & & & $0.189^{\star \star *}$ & & & & -0.013 \\
\hline & & & & 0.044 & & & & 0.053 & & & & 0.03 \\
\hline$\Delta$ Suburban PC Units & & & & $\begin{array}{l}0.231^{\star * *} \\
0.036\end{array}$ & & & & $\begin{array}{l}0.111 \\
0.091\end{array}$ & & & & $\begin{array}{l}0.161^{\text {** }} \\
0.067\end{array}$ \\
\hline Full Controls & $\mathrm{x}$ & $\mathrm{x}$ & $\mathrm{x}$ & $x$ & $\mathrm{x}$ & $\mathrm{x}$ & $\mathrm{x}$ & $x$ & $\mathrm{x}$ & $x$ & $\mathrm{x}$ & $\mathrm{X}$ \\
\hline MSA FE & $x$ & $x$ & $x$ & $x$ & $x$ & $x$ & $x$ & $x$ & $x$ & $x$ & $x$ & $X$ \\
\hline $\mathrm{N}$ & 24938 & 24938 & 24938 & 24938 & 12456 & 12456 & 12456 & 12456 & 12607 & 12607 & 12607 & 12607 \\
\hline
\end{tabular}

standard errors below coefficients

${ }^{*} p<.1,{ }^{* *} p<.05,{ }^{* * *} p<.01$

See Table 5 for full list of controls. 
Table 7 Metropolitan Minority/White Segregation

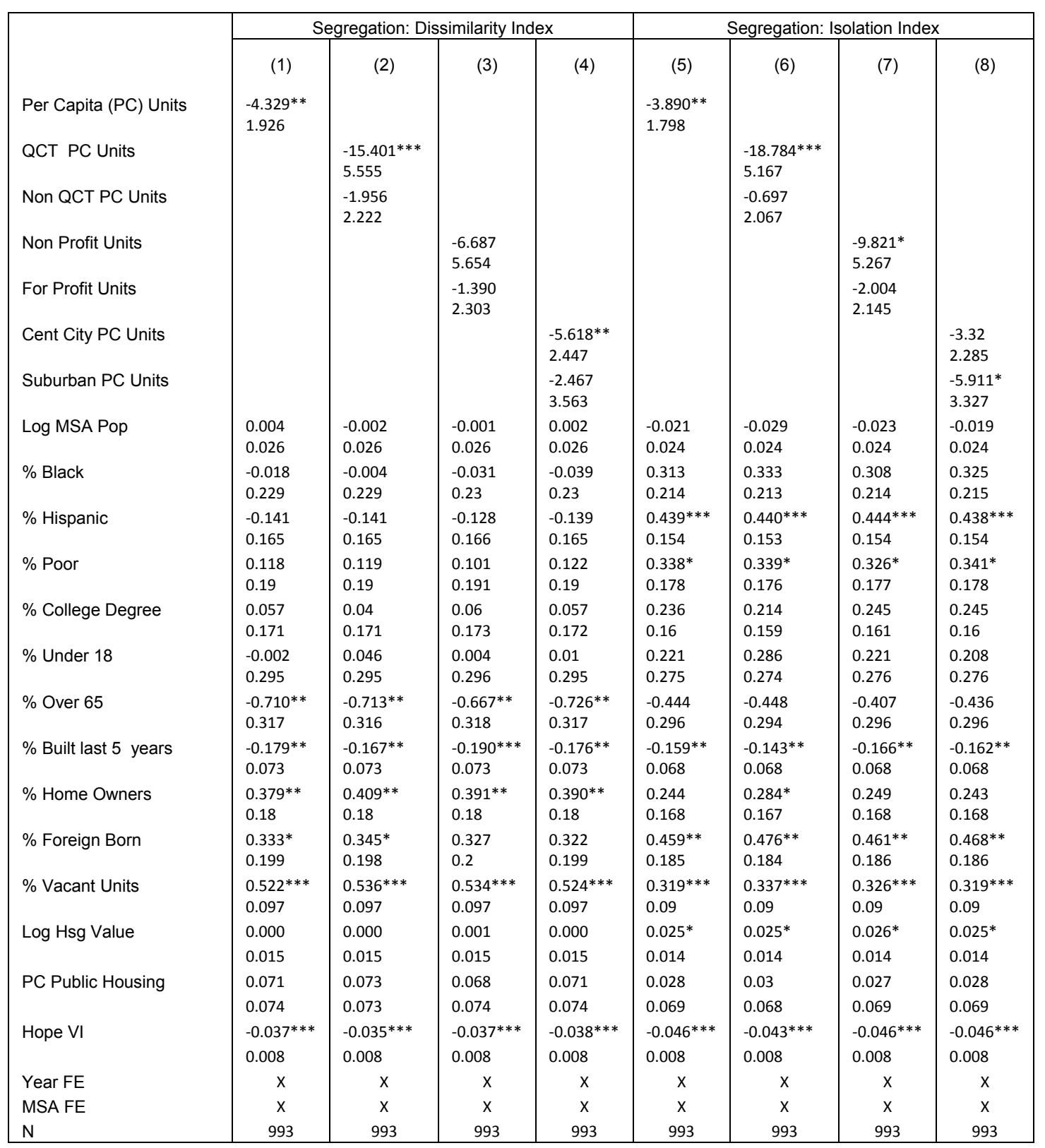

standard errors below coefficients

${ }^{*} \mathrm{p}<.1,{ }^{* \star} \mathrm{p}<.05,{ }^{* \star \star} \mathrm{p}<.01$ 


\section{Appendix A Segregation measures}

Dissimilarity Index. This is the most widely used measure of segregation, described as measuring the unevenness of a population's distribution. A dichotomous index, it captures the extent to which two groups (for example, minority and white) sort differently across neighborhoods within a metropolitan area. While this measure has its weaknesses (see James and Taeuber, 1985; Reardon and Firebaugh, 2002), it has been used extensively in both the residential and school segregation literatures, and has general intuitive appeal. Here, the index can be interpreted as the share of minority residents who would have to be redistributed in order for minorities and whites to have the identical distributions. Thus, when there is no segregation the index is zero, and with complete segregation, it equals one. The index between demographic group $\mathrm{j}$ (e.g. white) and $\mathrm{k}$ (e.g. minority) is calculated as follows:

$$
D=\frac{1}{2} \sum_{i}^{M}\left|\frac{N_{k i}}{N_{k}}-\frac{N_{j i}}{N_{j}}\right|
$$

where

$N_{j i}, N_{k i}=$ the number of people of group j, k in census tract i, M tracts in total $N_{j}, N_{k}=$ the number of people of group j, k in aggregate

Isolation Index. This index captures the social isolation of groups, or the extent to which minorities live in census tracts with other minorities. The isolation index is equivalent to the tract minority concentration experienced by the average minority person in an MSA. While the dissimilarity and isolation indices are clearly related, prior work has shown that they are far from perfectly correlated. ${ }^{48}$

The Isolation index of group k (e.g. minority) is:

$$
{ }_{k} I_{k}=\sum_{i}^{M}\left|\frac{N_{k i}}{N_{k}} * \frac{N_{k i}}{N_{i}}\right|
$$

where

$N_{k i}=$ the number of people of group k in tract i, M tracts in total

$N_{k}=$ the number of people of group k in aggregate

\footnotetext{
${ }^{48}$ Particularly relevant here, changes in these measures are not highly correlated over time.
} 
Appendix B1 Metropolitan Racial Segregation: Black/White

\begin{tabular}{|c|c|c|c|c|c|c|c|c|}
\hline \multirow{4}{*}{ Per Capita (PC) Units } & \multicolumn{4}{|c|}{ Segregation: Dissimilarity Index } & \multicolumn{4}{|c|}{ Segregation: Isolation Index } \\
\hline & $(1)$ & $(2)$ & (3) & $(4)$ & (5) & (6) & $(7)$ & (8) \\
\hline & $-4.190 *$ & & & & $-3.836 * *$ & & & \\
\hline & 2.157 & & & & 1.618 & & & \\
\hline \multirow[t]{2}{*}{ QCT PC Units } & & 2.539 & & & & $-12.526 * * *$ & & \\
\hline & & 6.236 & & & & 4.668 & & \\
\hline \multirow[t]{2}{*}{ Non QCT PC Units } & & $-5.633^{* *}$ & & & & -1.973 & & \\
\hline & & 2.495 & & & & 1.867 & & \\
\hline \multirow[t]{2}{*}{ Non Profit Units } & & & 0.186 & & & & -6.997 & \\
\hline & & & 6.324 & & & & 4.74 & \\
\hline \multirow[t]{2}{*}{ For Profit Units } & & & -3.863 & & & & -2.92 & \\
\hline & & & 2.576 & & & & 1.93 & \\
\hline \multirow[t]{2}{*}{ Cent City PC Units } & & & & $-7.753 * * *$ & & & & -2.716 \\
\hline & & & & 2.733 & & & & 2.052 \\
\hline \multirow[t]{2}{*}{ Suburban PC Units } & & & & 1.314 & & & & $-7.465 * *$ \\
\hline & & & & 3.979 & & & & 2.989 \\
\hline \multirow[t]{2}{*}{ Log MSA Pop } & $-0.055^{*}$ & $-0.051^{*}$ & $-0.055^{*}$ & $-0.060 * *$ & $-0.055^{* *}$ & $-0.060 * * *$ & $-0.056 * *$ & $-0.051 * *$ \\
\hline & 0.029 & 0.029 & 0.029 & 0.029 & 0.022 & 0.022 & 0.022 & 0.022 \\
\hline \multirow[t]{2}{*}{$\%$ Black } & $0.646 * *$ & $0.637^{* *}$ & $0.624 * *$ & $0.593^{* *}$ & $0.606 * * *$ & $0.618 * * *$ & $0.598 * * *$ & $0.632 * * *$ \\
\hline & $\begin{array}{l}0.257 \\
-\end{array}$ & $\begin{array}{l}0.257 \\
-\end{array}$ & $\begin{array}{l}0.257 \\
-\end{array}$ & 0.257 & 0.192 & 0.192 & $\begin{array}{l}0.193 \\
-\end{array}$ & 0.193 \\
\hline \multirow[t]{2}{*}{$\%$ Hispanic } & $0.522 * * *$ & $0.522 * * *$ & $0.505^{* * *}$ & $-0.519 * * *$ & $-0.483 * * *$ & $-0.483 * * *$ & $0.476 * * *$ & $-0.486 * * *$ \\
\hline & 0.185 & 0.185 & 0.185 & 0.185 & 0.139 & 0.138 & 0.139 & 0.139 \\
\hline \multirow[t]{2}{*}{$\%$ Poor } & $-0.420 * *$ & $-0.421 * *$ & $-0.442 * *$ & $-0.414^{*}$ & 0.037 & 0.038 & 0.023 & 0.041 \\
\hline & 0.213 & 0.213 & 0.213 & 0.212 & 0.16 & 0.159 & 0.16 & 0.16 \\
\hline \multirow[t]{2}{*}{$\%$ College Degree } & -0.016 & -0.006 & -0.036 & -0.024 & 0.01 & -0.003 & 0.01 & 0.023 \\
\hline & 0.192 & 0.192 & 0.193 & 0.192 & 0.144 & 0.144 & 0.145 & 0.144 \\
\hline \multirow[t]{2}{*}{$\%$ Under 18} & $1.047 * * *$ & $1.017^{* * *}$ & $1.043 * * *$ & $1.084^{* * *}$ & 0.033 & 0.071 & 0.03 & 0.01 \\
\hline & 0.33 & 0.331 & 0.331 & 0.33 & 0.248 & 0.248 & 0.248 & 0.248 \\
\hline \multirow[t]{2}{*}{$\%$ Over 65} & 0.201 & 0.202 & 0.221 & 0.156 & $-0.456^{*}$ & $-0.458 *$ & -0.428 & $-0.440 *$ \\
\hline & 0.355 & 0.355 & 0.355 & 0.354 & 0.266 & 0.265 & 0.266 & 0.266 \\
\hline \multirow[t]{2}{*}{$\%$ Built last 5 years } & 0.067 & 0.06 & 0.057 & 0.078 & -0.017 & -0.008 & -0.024 & -0.022 \\
\hline & 0.082 & 0.082 & 0.082 & 0.082 & 0.061 & 0.061 & 0.061 & 0.061 \\
\hline \multirow[t]{2}{*}{$\%$ Home Owners } & $0.703 * * *$ & $0.685^{* * *}$ & $0.704^{* * *}$ & $0.725^{* * *}$ & $0.528 * * *$ & $0.552^{* * *}$ & $0.529 * * *$ & $0.522^{* * *}$ \\
\hline & 0.201 & 0.202 & 0.202 & 0.201 & 0.151 & 0.151 & 0.151 & 0.151 \\
\hline \multirow[t]{2}{*}{$\%$ Foreign Born } & $0.409 *$ & $0.402^{*}$ & $0.419^{*}$ & $0.380^{*}$ & $0.348^{* *}$ & $0.358^{* *}$ & $0.355^{* *}$ & $0.364 * *$ \\
\hline & 0.222 & 0.222 & 0.223 & 0.222 & 0.167 & 0.166 & 0.167 & 0.167 \\
\hline \multirow[t]{2}{*}{$\%$ Vacant Units } & $0.827 * * *$ & $0.819 * * *$ & $0.828 * * *$ & $0.829 * * *$ & $0.406 * * *$ & $0.417 * * *$ & $0.409 * * *$ & $0.405^{* * *}$ \\
\hline & 0.108 & 0.108 & 0.109 & 0.108 & 0.081 & 0.081 & 0.081 & 0.081 \\
\hline \multirow[t]{2}{*}{ Log Hsg Value } & -0.014 & -0.014 & -0.013 & -0.014 & 0.008 & 0.008 & 0.008 & 0.008 \\
\hline & 0.017 & 0.017 & 0.017 & 0.017 & 0.013 & 0.013 & 0.013 & 0.013 \\
\hline PC Public Housing & 0.064 & 0.063 & 0.06 & 0.065 & 0.008 & 0.009 & 0.006 & 0.008 \\
\hline & 0.082 & 0.082 & 0.083 & 0.082 & 0.062 & 0.062 & $\begin{array}{l}0.062 \\
-\end{array}$ & 0.062 \\
\hline Hope VI & 0.003 & 0.001 & 0.003 & 0.002 & $-0.030 * * *$ & $-0.028 * * *$ & $0.030 * * *$ & $-0.029 * * *$ \\
\hline & 0.009 & 0.009 & 0.009 & 0.009 & 0.007 & 0.007 & 0.007 & 0.007 \\
\hline Year FE & $x$ & $x$ & $x$ & $x$ & $x$ & $x$ & $x$ & $x$ \\
\hline MSA FE & $x$ & $x$ & $x$ & $x$ & $x$ & $x$ & $x$ & $x$ \\
\hline $\mathrm{N}$ & 993 & 993 & 993 & 993 & 993 & 993 & 993 & 993 \\
\hline
\end{tabular}

standard errors below coefficients

${ }^{*} p<.1,{ }^{* *} p<.05,{ }^{* \star *} p<.01$ 
Appendix B2 Metropolitan Racial Segregation: Hispanic/White

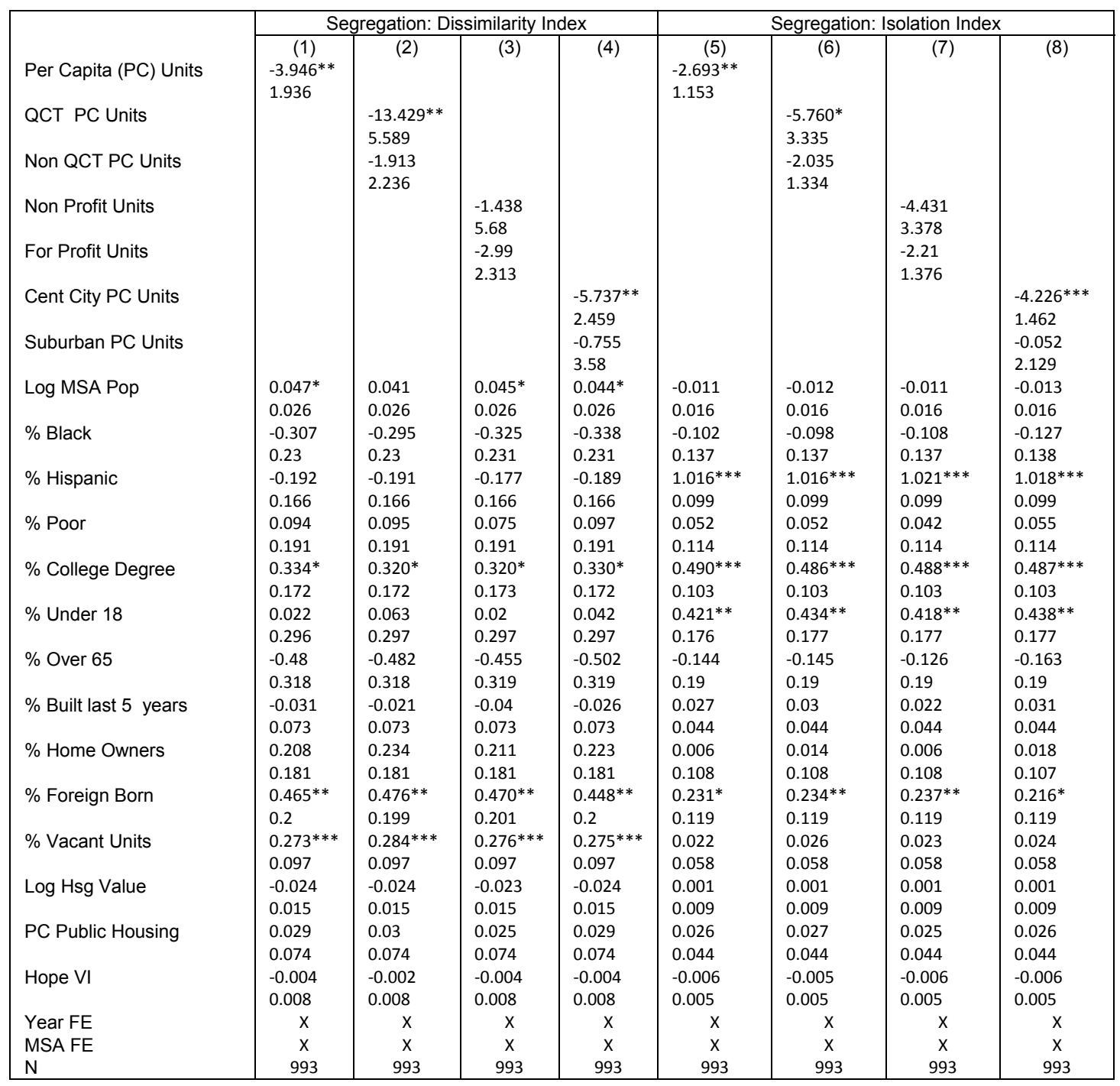

standard errors below coefficients

${ }^{*} p<.1,{ }^{* *} p<.05,{ }^{* * *} p<.01$ 